\title{
Acute Kidney Injury in Pregnancy: A Single-Center Study in Tunisia
}

\author{
Imen Gorsane, Madiha Mahfoudhi*, Mounira El Euch, Taieb Ben Abdallah \\ Internal Medicine A Department, Charles Nicolle Hospital, Tunis, Tunisia \\ Email: " madiha mahfoudhi@yahoo.fr
}

Received 17 May 2015; accepted 10 October 2015; published 13 October 2015

Copyright @ 2015 by authors and Scientific Research Publishing Inc.

This work is licensed under the Creative Commons Attribution International License (CC BY).

http://creativecommons.org/licenses/by/4.0/

(c) (i) Open Access

\begin{abstract}
Acute kidney injury is a rare but serious complication of pregnancy. It is still common in developing countries. The causes can be varied. It is imperative to distinguish these conditions to make appropriate therapeutic decisions which can be lifesaving for the mother and fetus. This study examined the incidence and etiology of acute kidney injury in pregnancy, the morbidity, fetomaternal mortality, and renal prognosis among pregnant patients developing acute kidney injury. This is a retrospective observational study involving cases of acute kidney injury during pregnancy and hospitalized in our department from 1995 to 2015. The study involved 10 patients. The average age of patients was 31.6 years. Personal history of preeclampsia was found in 2 patients. The average term of pregnancy in which appeared the acute kidney injury was 33 weeks. All patients had preeclampsia. Five of them had a retro-placental hematoma, 2 had eclampsia and another post-partum hemorrhage. Five patients underwent renal biopsy for a persistent acute kidney injury with an average delay of 26 days. The histological results were: partial cortical necrosis in one case, thrombotic microangiopathy in two cases, acute tubular necrosis in one case, and membranoproliferative glomerulonephritis in one case. Six of our patients had an antihypertensive treatment. Seven patients have required renal replacement therapy. The ultimate evolution was good in 9 patients with recovery of diuresis and total recovery of renal function. Only one patient had kept with advanced renal failure requiring hemodialysis. She has been transplanted after 2 years with normal graft function. The pregnancy care and quality of access to care remain fundamental to prevent complications of pregnancy, including acute kidney injury.
\end{abstract}

\section{Keywords}

Acute Renal Failure, Pregnancy, Preeclampsia

\footnotetext{
${ }^{*}$ Corresponding author.
}

How to cite this paper: Gorsane, I., Mahfoudhi, M., El Euch, M. and Abdallah, T.B. (2015) Acute Kidney Injury in Pregnancy: A Single-Center Study in Tunisia. International Journal of Clinical Medicine, 6, 729-733. 


\section{Introduction}

Acute kidney injury (AKI) is costly and is associated with increased maternal and perinatal mortality and morbidity [1]. The incidence of AKI in pregnancy declined significantly over the second half of the 20th century in industrialized countries thanks to advances in contraception, legalizing abortion and more careful monitoring of the perinatal period [2]. It currently affects 1 per 20,000 pregnancies [2]. The incidence of pregnancy-related acute renal failure in the developed countries is $1 \%-2.8 \%$, whereas in the developing countries this is about $4.2 \%-15 \%$ [3]. Hypertensive complications of pregnancy (preeclampsia/eclampsia or hemolysis, elevated liver enzymes, and low platelets count syndrome) are the leading cause of AKI in pregnancy worldwide [4].

It is essential to focus on the prevention, periodic evaluation of pregnant women and improvement in the care during the peripartum period to improve maternal and perinatal outcomes.

The objective of our study is to report the etiology and fetomaternal outcome of AKI during pregnancy.

\section{Patients and Methods}

1) Inclusion criteria

-Pregnant women or postpartum patients with AKI with or without oligoanuria defined by elevated creatinine levels $>130 \mu \mathrm{mol} / \mathrm{l}$.

2) Exclusion criteria

-Pregnant women with pre-existing kidney disease.

-Pregnant women with a known history of diabetes and hypertension.

3) Methods

It is a retrospective study in the Nephrology department of Medicine A at the Charles Nicolle Hospital in Tunis from 1995 to 2015.

Ten patients were selected for this study. Patient records, demographic data, urine output on admission and preceding history of antepartum hemorrhage, post-partum hemorrhage, septicemia and operative interventions were noted and need for dialysis was considered. Patients were thoroughly examined and baseline biochemical investigations and renal and obstetrical ultrasound were performed on each patient.

\section{Results}

The incidence of AKI was of 0.5 cases/year. The average age of patients was 31.6 years (23 - 41 years), fifty percent were primiparous. Personal history of preeclampsia was found in 2 patients. The average pregnancy term when appears AKI was 33 weeks.

Oedema, hypertension and proteinuria were found in $90 \%$ of patients. Only one patient had conserved diuresis.

A vaginal delivery was performed in $60 \%$ of cases. One child was born at term, 4 were premature had and 5 had a fetal death.

The mean creatinine was $425 \mu \mathrm{mol} / \mathrm{l}(140$ - $1000 \mu \mathrm{mol} / \mathrm{l})$. The mean hemoglobin level was $6.37 \mathrm{~g} / \mathrm{dl}$ (4.6 - 9.7 $\mathrm{g} / \mathrm{dl})$. Four patients had thrombocytopenia with an average of $110,000 / \mathrm{mm}^{3}\left(91,000-140,000 / \mathrm{mm}^{3}\right)$. Liver function tests were normal in all patients. Renal ultrasound was normal in all patients, obstetric ultrasound showed an increase in vascular resistance with the presence of a nuch in 4 patients.

All patients had preeclampsia with epigastric and right upper quadrant pain, nausea, vomiting, headache, blurry vision and the sudden onset of edema. Five of them had a retro-placental hematoma with back pain and vaginal bleeding, 2 had eclampsia with tonic-clonic seizures and another post-partum hemorrhage. Five patients underwent renal biopsy on the post-partum for a persistent AKI with an average delay of 26 days. In one patient, histology showed a partial cortical necrosis with lesions of focal segmental, in two patients it was a thrombotic microangiopathy, in one patient, acute tubular necrosis and a membranoproliferative glomerulonephritis in one patient.

Six patients needed dialysis in addition to antihypertensive therapy. One patient was dialyzed only.

The ultimate evolution was good in 9 patients with recovery of diuresis and total recovery of renal function. Only one patient had kept with advanced renal failure requiring hemodialysis. She has been transplanted after 2 years with normal graft function.

Table 1 shows the summary results. 
Table 1. Summary of results.

\begin{tabular}{|c|c|c|c|c|c|c|c|c|c|c|}
\hline $\mathbf{P}$ & $\begin{array}{c}\text { Age } \\
\text { (years) }\end{array}$ & $\begin{array}{c}\text { PT } \\
\text { (weeks) }\end{array}$ & $\underset{(\mathbf{m m H g})}{\mathbf{A P}}$ & Diuresis & $\begin{array}{c}\text { Creatinine } \\
\text { clearance } \\
(\mathrm{ml} / \mathrm{mn})\end{array}$ & Etiologies & HD & KB & $\begin{array}{c}\text { Evolution } \\
\text { of RF }\end{array}$ & $\begin{array}{c}\text { Evolution of } \\
\text { NB }\end{array}$ \\
\hline 1 & 26 & 33 & $80 / 50$ & Oliguria & 5.92 & PE + HRP & + & & Recovery & Fetal death \\
\hline 2 & 29 & 30 & $85 / 50$ & Anuria & 7.31 & $\mathrm{PE}+\mathrm{HRP}$ & + & $\begin{array}{c}\text { Partial cortical } \\
\text { necrosis + lesions } \\
\text { of focal segmental }\end{array}$ & Recovery & Fetal death \\
\hline 3 & 24 & 31 & $150 / 110$ & Anuria & 7 & $\mathrm{PE}+\mathrm{PPH}$ & + & $\begin{array}{l}\text { Thrombotic } \\
\text { microangiopathy }\end{array}$ & $\begin{array}{l}\text { Chronic } \\
\text { HD/RT }\end{array}$ & Premature \\
\hline 4 & 39 & 32 & $160 / 100$ & Oliguria & 10.46 & $\mathrm{PE}$ & & & Recovery & Fetal death \\
\hline 5 & 23 & 32 & $140 / 90$ & Oliguria & 7.56 & $\mathrm{PE}+\mathrm{E}$ & + & & Recovery & Premature \\
\hline 6 & 26 & 33 & $140 / 90$ & Normal & 48.3 & $\mathrm{PE}+\mathrm{HRP}$ & & & Recovery & Premature \\
\hline 7 & 33 & 33 & $160 / 100$ & Oliguria & 40.7 & $\mathrm{PE}+\mathrm{HRP}$ & & Acute tubular necrosis & Recovery & Fetal death \\
\hline 8 & 34 & 32 & $170 / 100$ & Oliguria & 7.38 & $\mathrm{PE}$ & + & $\begin{array}{l}\text { Membranoproliferative } \\
\text { glomerulonephritis }\end{array}$ & Recovery & Premature \\
\hline 9 & 33 & 29 & $140 / 100$ & Oliguria & 9.7 & $\mathrm{PE}+\mathrm{HRP}+\mathrm{E}$ & + & & Recovery & Fetal death \\
\hline 10 & 32 & 38 & $150 / 90$ & Oliguria & 7.37 & $\mathrm{PE}$ & + & $\begin{array}{l}\text { Thrombotic } \\
\text { microangiopathy }\end{array}$ & Recovery & Born at term \\
\hline
\end{tabular}

P: patient, PT: pregnancy term, AP: arterial pressure, HD: hemodialysis, KB: kidney biopsy, RF: renal function, NB: newborn, PE: preeclampsia, E: eclampsia, RPH: retro-placental hematoma, PPH: post-partum hemorrhage, RT: renal transplantation.

\section{Discussion}

Acute renal failure is a most challenging clinical problem when it occurs in pregnancy. It requires an understanding of the normal physiology of the kidney in pregnancy [5]. Its definition, and hence, its incidence, varies widely in published studies from mild increase in serum creatinine $>0.8 \mathrm{mg} / \mathrm{dl}(70 \mu \mathrm{mol} / \mathrm{l})$ to dialysis requirement [6] [7]. The diagnosis of AKI in pregnancy is generally based on the serum creatinine increase. The usual formulas for estimating glomerular filtration rate are not validated in this population [2].

A set of systemic and renal physiological adaptive mechanisms occur during a normal gestation that will constrain several changes in laboratory parameters of renal function, electrolytes, fluid and acid-base balances [2]. These changes are characterized by an increase in renal flow at the beginning of pregnancy up to $80 \%$ at 6 months of pregnancy. Glomerular filtration is increased by $15 \%$ at the beginning of pregnancy, by $50 \%-70 \%$ at the end. Serum creatinine level decreases during normal pregnancy mainly because of the combination of blood volume expansion, hyperfiltration, and oncotic pressure decrease, and it reaches levels around 0.6 - $0.7 \mathrm{mg} / \mathrm{dl}$ during the third trimester [4].

As in the general population, AKI can occur from prerenal, intrinsic, and post-renal causes. Major causes of pre-renal azotemia include hyperemesis gravidarum and uterine hemorrhage in the setting of placental abruption. Intrinsic etiologies include infections from acute pyelonephritis and septic abortion, bilateral cortical necrosis, and acute tubular necrosis. Specific conditions that lead to AKI during the second and third trimesters are preeclampsia, HELLP (Haemolysis, Elevated Liver enzyme, Low Platelet count) syndrome, acute fatty liver of pregnancy (AFLP) and thrombotic microangiopathies [1] [8]. Early recognition of these disorders is essential to timely treatment that can improve both maternal and fetal outcomes [9].

Uterine haemorrhage and secondary hypotension can be responsible directly for acute tubular necrosis in 7\% $39 \%$ of cases of AKI [10].

Pre-eclampsia/eclampsia is a disorder of pregnancy characterized by high blood pressure and proteinuria which affects between $2 \%$ - $8 \%$ of pregnancies worldwide [11]. Convincing data have linked pre-eclampsia/ eclampsia to an increase in circulating antiangiogenic factors soluble Flt 1 and endoglin, which induce endothelial cell dysfunction, hypertension, and proteinuria [3].

HELLP syndrome is a leading cause of AKI in pregnancy. HELLP syndrome accounts for $40 \%$ of all cases of AKI in pregnancy and up to $60 \%$ of severe cases [12] [13]. AKI associated with HELLP syndrome, even in its severe forms requiring dialysis, usually retains a favorable renal outcome. Most patients $(93 \%-100 \%)$ are 
usually discharged without any significant residual renal impairment [13] [14].

AFLP is characterized by jaundice and liver dysfunction. It can occur at the end of pregnancy or in the early puerperium and is a rare cause of AKI [15].

For our patients, all had preeclampsia. Five of them had a retro-placental hematoma, 2 had eclampsia and another post-partum hemorrhage.

Because patients with chronic renal disease may present with worsening proteinuria, hypertension, and renal function, these disorders must be excluded from those conditions that cause acute deterioration of renal failure in otherwise normal women during pregnancy [5].

The safety as well as indications for performing renal biopsies during pregnancy is currently debatable and reports of excessive bleeding and other complications in pregnant women have led some to consider pregnancy as a relative contraindication for renal biopsy [16].

In our study, five patients underwent renal biopsy in post-partum. Histology showed a partial cortical necrosis with lesions of focal segmental, in two patients it was a thrombotic microangiopathy, in one patient, acute tubular necrosis and a membranoproliferative glomerulonephritis in one patient.

By understanding the causes of renal functional deterioration in pregnancy, appropriate therapeutic decisions to preserve both maternal and fetal well-being [5]. In many cases, delivery of the fetus is the recommended therapeutic option, with additional therapies indicated for each specific disease entity [1]. Typically AFLP and HELLP improve after delivery of the fetus, whereas plasma exchange is the first-line treatment for thrombotic microangiopathies [17].

Our study has limitations due to its retrospective nature, the small number and declining incidence of AKI during the pregnancy that makes the event becomes less and less frequent.

\section{Conclusion}

An understanding of the renal physiologic changes that occur during pregnancy is essential for proper evaluation, diagnosis, and management of AKI. The degree of renal dysfunction is the major determining factor of pregnancy outcomes, which may further be complicated by a prior history of hypertension.

\section{Conflict of Interests}

The authors declare that there is no conflict of interests regarding the publication of this paper.

\section{References}

[1] Nwoko, R., Plecas, D. and Garovic, V.D. (2012) Acute Kidney Injury in the Pregnant Patient. Clinical Nephrology, 78, 478-486. http://dx.doi.org/10.5414/CN107323

[2] Machado, S., Figueiredo, N., Borges, A., Pais, S.J.M., Freitas, L., Moura, P., et al. (2012) Acute Kidney Injury in Pregnancy: A Clinical Challenge. Journal of Nephrology, 25, 19-30. http://dx.doi.org/10.5301/jn.5000013

[3] Goplani, K.R., Shah, P.R., Gera, D.N., Gumber, M., Dabhi, M., Feroz, A., et al. (2008) Pregnancy-Related Acute Renal failure: A Single-Center Experience. Indian Journal of Nephrology, 18, 17-21. http://dx.doi.org/10.4103/0971-4065.41283

[4] Fakhouri, F., Vercel, C. and Frémeaux-Bacchi, V. (2012) Obstetric Nephrology: AKI and Thrombotic Microangiopathies in Pregnancy. Clinical Journal of the American Society of Nephrology, 7, 2100-2106. http://dx.doi.org/10.2215/CJN.13121211

[5] Krane, N.K. (1988) Acute Renal Failure in Pregnancy. Archives of Internal Medicine, 148, 2347-2357. http://dx.doi.org/10.1001/archinte.1988.00380110013004

[6] Prakash, J., Niwas, S.S., Parekh, A., Pandey, L.K., Sharatchandra, L., Arora, P., et al. (2010) Acute Kidney Injury in Late Pregnancy in Developing Countries. Ren Fail, 32, 309-313. http://dx.doi.org/10.3109/08860221003606265

[7] Ganesan, C. and Maynard, S.E. (2011) Acute Kidney Injury in Pregnancy: The Thrombotic Microangiopathies. Journal of Nephrology, 24, 554-563. http://dx.doi.org/10.5301/JN.2011.6250

[8] Aggarwal, R.S., Mishra, V.V., Jasani, A.F. and Gumber, M. (2014) Acute Renal Failure in Pregnancy: Our Experience. Saudi Journal of Kidney Diseases and Transplantation, 25, 450-455. http://dx.doi.org/10.4103/1319-2442.128621

[9] Gyamlani, G. and Geraci, S.A. (2013) Kidney Disease in Pregnancy: (Women’s Health Series). Southern Medical Journal, 106, 519-525. http://dx.doi.org/10.1097/SMJ.0b013e3182a5f137 
[10] Grünfeld, J.P., Ganeval, D. and Bournérias, F. (1980) Acute Renal Failure in Pregnancy. Kidney International, 18, 179-191. http://dx.doi.org/10.1038/ki.1980.127

[11] Godara, S.M., Kute, V.B., Trivedi, H.L., Vanikar, A.V., Shah, P.R., Gumber, M.R., et al. (2014) Clinical Profile and Outcome of Acute Kidney Injury Related to Pregnancy in Developing Countries: A Single-Center Study from India. Saudi Journal of Kidney Diseases and Transplantation, 25, 906-911. http://dx.doi.org/10.4103/1319-2442.135215

[12] Gul, A., Aslan, H., Cebeci, A., Polat, I., Ulusoy, S. and Ceylan, Y. (2004) Maternal and Fetal Outcomes in HELLP Syndrome Complicated with Acute Renal Failure. Ren Fail, 26, 557-562. http://dx.doi.org/10.1081/JDI-200031750

[13] Drakeley, A.J., Le Roux, P.A., Anthony, J. and Penny, J. (2002) Acute Renal Failure Complicating Severe Preeclampsia Requiring Admission to an Obstetric Intensive Care Unit. American Journal of Obstetrics \& Gynecology, 186, 253-256. http://dx.doi.org/10.1067/mob.2002.120279

[14] Selçuk, N.Y., Odabas, A.R., Cetinkaya, R., Tonbul, H.Z. and San, A. (2000) Outcome of Pregnancies with HELLP Syndrome Complicated by Acute Renal Failure (1989-1999). Ren Fail, 22, 319-327. http://dx.doi.org/10.1081/JDI-100100875

[15] Beaufils, M. (1998) Acute Renal Failure in a Special Setting. In: Stewart Cameron, J., Grunfeld, J.P., Kerr, D.N.S., Ritz, E. and Winearls, C.G., Eds., Oxford Textbook of Clinical Nephrology, Oxford University Press, Oxford, 17041713.

[16] Kuller, J.A., D’Andrea, N.M. and McMahon, M.J. (2001) Renal Biopsy and Pregnancy. American Journal of Obstetrics \& Gynecology, 184, 1093-1096. http://dx.doi.org/10.1067/mob.2001.114917

[17] Mattar, F. and Sibai, B.M. (2000) Eclampsia. VIII. Risk Factors for Maternal Morbidity. American Journal of Obstetrics \& Gynecology, 182, 307-312. http://dx.doi.org/10.1016/S0002-9378(00)70216-X

\section{Abbreviations}

AFLP: Acute Fatty Liver of Pregnancy.

AKI: Acute Kidney Injury.

HELLP: Haemolysis, Elevated Liver enzyme, Low Platelet count. 